\title{
Localisation of laminin within Plasmodium berghei oocysts and the midgut epithelial cells of Anopheles stephensi Adéla Nacer ${ }^{1}$, Karen Walker ${ }^{2}$ and Hilary Hurd*1
}

\author{
Address: ${ }^{1}$ Centre for Applied Entomology and Parasitology, Institute for Science and Technology in Medicine, School of Life Sciences, Keele \\ University, Keele, Staffordshire, ST5 5BG, UK and ${ }^{2}$ Central Electron Microscope Unit, School of Life Sciences, Keele University, Staffordshire, UK \\ Email: Adéla Nacer - dela.nacer@gmail.com; Karen Walker - k.walker@cns.keele.ac.uk; Hilary Hurd* - h.hurd@keele.ac.uk \\ * Corresponding author
}

Published: 22 September 2008

Parasites \& Vectors 2008, I:33 doi:10.1/86/1756-3305-I-33
Received: 17 July 2008

Accepted: 22 September 2008

This article is available from: http://www.parasitesandvectors.com/content/I/I/33

(C) 2008 Nacer et al; licensee BioMed Central Ltd.

This is an Open Access article distributed under the terms of the Creative Commons Attribution License (http://creativecommons.org/licenses/by/2.0), which permits unrestricted use, distribution, and reproduction in any medium, provided the original work is properly cited.

\begin{abstract}
Background: Oocysts of the malaria parasite form and develop in close proximity to the mosquito midgut basal lamina and it has been proposed that components of this structure play a crucial role in the development and maturation of oocysts that produce infective sporozoites. It is further suggested that oocysts incorporate basal lamina proteins into their capsule and that this provides them with a means to evade recognition by the mosquito's immune system. The site of production of basal lamina proteins in insects is controversial and it is still unclear whether haemocytes or midgut epithelial cells are the main source of components of the mosquito midgut basal lamina. Of the multiple molecules that compose the basal lamina, laminin is known to interact with a number of Plasmodium proteins. In this study, the localisation of mosquito laminin within the capsule and cytoplasm of Plasmodium berghei oocysts and in the midgut epithelial cells of Anopheles stephensi was investigated.
\end{abstract}

Results: An ultrastructural examination of midgut sections from infected and uninfected An. stephensi was performed. Post-embedded immunogold labelling demonstrated the presence of laminin within the mosquito basal lamina. Laminin was also detected on the outer surface of the oocyst capsule, incorporated within the capsule and associated with sporozoites forming within the oocysts. Laminin was also found within cells of the midgut epithelium, providing support for the hypothesis that these cells contribute towards the formation of the midgut basal lamina.

Conclusion: We suggest that ookinetes may become coated in laminin as they pass through the midgut epithelium. Thereafter, laminin secreted by midgut epithelial cells and/or haemocytes, binds to the outer surface of the oocyst capsule and that some passes through and is incorporated into the developing oocysts. The localisation of laminin on sporozoites was unexpected and the importance of this observation is less clear.

\section{Background}

Malaria, a vector borne disease caused by an intracellular obligate protozoan parasite of the genus Plasmodium, is responsible for the loss of approximately 2 million lives each year [1]. Control of the disease by drug use or elimi- nation of the vector is becoming more difficult as drug resistance in the parasite and insecticide resistance in the mosquito is widespread. Recent efforts have focused on finding new ways to interrupt the transmission of the parasite via mosquitoes; a strategy referred to as transmission 
blocking. In addition to the use of insecticide treated bednets $[2,3]$ several new approaches are being explored including transmission blocking vaccine development. The current emphasis on the development of new transmission blocking strategies to control malaria, and in particular the genetic manipulation of mosquitoes, make it essential to achieve a better understanding of the interactions between the vector and parasite.

Infection of the mosquito host occurs when Plasmodium gametocytes are ingested during a blood meal. Gametogenesis is triggered, allowing the release of the macrogametes from their host red blood cells and the assembly and release of the microgametes; a process termed exflagellation. Fertilisation rapidly follows and a zygote is produced [4]. Once this occurs, the parasite begins to change to become characteristic of the apicomplexan invasive stages. Within 10-25 hours, the zygote gives rise to an ookinete, a motile stage of the parasite life cycle that migrates out of the blood bolus and traverses the peritrophic matrix. The ookinete then penetrates the midgut epithelium at the apical junction of two epithelial cells and may transiently traverse several cells before exiting the basolateral membrane of the midgut epithelium. There it stops beneath the basal lamina (BL) and transforms via a took stage [5] into a sessile spherical oocyst [4].

The oocyst is the longest developmental stage of the Plasmodium life cycle, lasting between 10-15 days dependent upon the species [6]. During this time the oocyst will grow in size from $\sim 5 \mu \mathrm{m}$ to $50 \mu \mathrm{m}$ and simultaneously undergo several rounds of nuclear division resulting in the production of up to 8000 haploid nuclei $[7,8]$. Sporozoites are formed by budding from the sporoblast(s) (for a review see [9]), formed by the retraction of the oocyst plasma membrane from the oocyst capsule [8-12]. In contrast to other apicomplexan parasites Plasmodium oocyst capsules do not appear to have an operculum for the release of sporozoites [10], instead, mature sporozoites egress from any point of the mature oocyst [13]. The oocyst capsule is a clearly distinct, electron dense, layer $0.1-1 \mu \mathrm{m}$ thick that encloses the oocyst and separates it from the adjacent mosquito tissue and BL $[8,11,12]$. Recently a Plasmodium protein specifically expressed in the capsule, PbCAP380, has been described [8]. Although the complete molecular composition of the capsule remains unknown, it has been proposed that it is derived from both parasite and mosquito proteins $[10,14]$; a hypothesis that has received some support as transgluaminase activity in oocysts suggests that mosquito proteins could be cross-linked into the capsule [15].

The BL is a complex meshwork of molecules. In mammals, the major components are laminin, collagen IV, entactin (nidogen), and perlecan [16]. The BL surrounds all epithelial sheets and is secreted by the epithelial cells that rest on it [17]. It has been implicated in diverse cellular functions including the ability to induce cell differentiation, to influence cell metabolism, organise proteins in adjacent plasma membranes and mediate cell migration $[16,17]$.

Similarly, the composition of the insect BL includes laminin, collagen IV, entactin, and perlecan [16,18-20]. A high degree of conservation of some BL proteins such as laminin and collagen type IV exists between mammals and insects $[16,21]$ but no fibronectin, thrombosbondin, von Willebrand factor, or elastin homologues have yet been identified in the model insect Drosophila melanogaster [16]. In contrast to other multicellular organisms, it has been proposed that the insect BL is secreted by haemocytes rather than epithelial cells [22-24]. Although the origin of insect BL is debatable $[19,21,23,25,26]$, there is evidence for haemocyte involvement in BL formation and repair. For example, haemocytes associate with the $\mathrm{BL}$ during metamorphosis and wound repair [27] and mRNA for BL components such as collagen IV is expressed in haemocytes [28].

It has been suggested that interactions with the BL are crucial for Plasmodium development within its mosquito vector $[10,25,29-33]$. Several key observations that led to the proposal of a role for the BL in oocyst development include: the developmental site of the oocyst beneath the BL $[33,34]$, the binding of parasite proteins to the $\mathrm{BL}$ $[29,30,35,36]$ and the reduction in the intensity of oocysts infection when BL components, or parasite proteins that interact with them, are knocked-down or disrupted, respectively $[25,29,37,38]$. Furthermore, injection of ookinetes into the haemocoel of $D$. melanogaster led to the development, and eventual sporogony, of oocysts that were attached to the BL of various organs [39].

Adhesion of laminin to ookinetes has been demonstrated in vitro [35] and in vivo [25,40] and several proteins expressed in ookinetes have been shown to bind to laminin (discussed in [41]). Although it has now been demonstrated that an association with BL components is not a requirement for transformation of ookinetes to oocysts in vitro [5], recent evidence points towards a role in parasite evasion of the mosquito immune response $[10,19,25,40]$. In particular, the melanisation of Sephadex beads by Aedes aegypti mosquitoes is greatly reduced when they are coated with the surface protein of $P$. gallinaceum ookinetes, Pg28, to which laminin was found to be bound [40]. Ookinetes are 'covered' in laminin prior to the completion of their migration through the midgut epithelium [25] and P. gallinaceum oocysts have been labelled by collagen IV and laminin antibodies in vivo, leading to the suggestion that the capsule of Plasmodium oocysts is composed of both 
parasite- and mosquito-derived proteins [10]. It should be noted that light microscopy does not allow for the distinction of the capsule from the $\mathrm{BL}$, which may explain why observations at the electron and light microscopy level have produced conflicting hypotheses concerning the relationship between the BL and oocysts. However, most authors agree that the $\mathrm{BL}$ is separate and morophologically distinct from the oocyst capsule $[12,14,42,43]$. In addition, some authors have proposed a more intimate association between the two, particularly with regards to the origin of the capsule $[10,14]$. For example, Melhorn et al. [14] described electron dense areas in the host cell adjacent to the oocyst capsule and surmised that material was secreted by the host-cell at these sites and used in the formation of the capsule. The role of the BL in oocyst development remains poorly understood, in particular with regards to the possible incorporation of BL components into the oocyst capsule.

Using post-embedded immunogold labelling electron microscopy, we show that the BL is in very close contact with, but distinct from, the capsule of $P$. berghei oocysts. In addition, we show that mosquito-derived laminin is incorporated into $P$. berghei oocysts 14 days post-infection. Finally, we present evidence that laminin may be produced by, or trafficked through, the midgut epithelium and discuss the implications of these results with regards to parasite development from the ookinete to the sporozoite.

\section{Results}

\section{General observations}

The midgut epithelia of An. stephensi uninfected and infected mosquitoes were surrounded with a BL of similar thickness (between $100-500 \mathrm{~nm}$ ) in all sections studied (Figure 1A and 1B). An infected midgut containing 32 oocysts and an uninfected midgut were selected for sectioning and subsequently, detailed analyses of laminin labelling were performed on five ultrathin sections from the infected midgut and four from the uninfected midgut.

Chain-specific $\beta$ and $\gamma$ Drosophila laminin antibodies [44] were used to label laminin in the ultrathin sections. These antibodies did not recognise mouse laminin, as determined by immunoblotting, but recognised a single band each when tested against the culture supernatant of Drosophila S2 cells (data not shown). In addition, labelling of whole Anopheles midguts was observed by indirect immunfluorescence assays (data not shown). No labelling was observed when a control rabbit IgG antibody (Sigma) was used, or when the primary antibody was omitted.

In order to further ensure that any labelling was not due to non-specific binding of the antibodies to the tissues, the density of gold particles in regions of interest was compared to control areas, namely; the resin in which the sample was embedded and the gut lumen. Labelling in these areas could indicate one of two different types of problems, non-specific binding resulting from lack of antibody specificity, or an excess of labelled antibody. The resin, which contained no biological material, was also used to verify the optimum concentration of antibodies to be used. The midgut lumen provided a biological control for the specificity of the antibodies, as laminin was not expected to be present there. Virtually no labelling was detected in the resin surrounding the sections at the antibody dilutions used in this study.

Oocysts at different stages of development, the majority of which contained fully formed sporozoites, were observed 14 days post-infection. A capsule was plainly visible surrounding the oocysts and clearly distinct from the BL. Laminin labelling using $30 \mathrm{~nm}$ gold particles was observed around the oocyst capsules and within the oocysts; primarily associated with developing sporozoites (Figure 2B). As no capsule-specific antibodies were available at the time, circumsporozoite protein (CSP) was used as a marker to delineate oocyst-specific structures, as it is not located within the capsule. Some infected midgut sections were also labelled with CSP using $10 \mathrm{~nm}$ gold particles and labelling was subsequently observed within $P$. berghei oocysts, around developing sporozoites and adjacent to the inner surface of the capsule (e.g. Figure 3B, 3C, $4 \mathrm{~B}$ and $4 \mathrm{C}$ ) as reported by previous studies [45-48]. Inspection of the sections revealed that a layer of BL of variable thickness surrounded oocysts in very close association with the oocysts' capsule. This layer of BL appeared to be thinner in areas of oocysts that would have protruded into the haemocoel than in areas of the capsule that were adjacent to the basal labyrinth of the midgut epithelial cells (Figure 4C).

\section{Laminin distribution in An. stephensi midgut epithelial cells}

Laminin was initially labelled using $30 \mathrm{~nm}$ gold particles and similar distribution patterns in the BL of uninfected and infected mosquito midguts were observed (Figure 1A and 1B). Particle size was then reduced to $10 \mathrm{~nm}$ as these gave a greater accuracy of labelling and a comparison of the density of laminin labelling associated with the midgut BL and control areas (resin and midgut lumen) demonstrated that BLs from both the infected and uninfected midguts contained a significantly higher density of gold particles than the control areas (Kruskal-Wallis: $\mathrm{H}_{(7)}=$ 59.8, $P<0.001$; Table 1). As can be seen from data in Table 1, some labelling was detected in the midgut lumens and this was at a higher density in the infected midgut sections compared to the uninfected sections. The reason for this observation is unclear; however, in both 

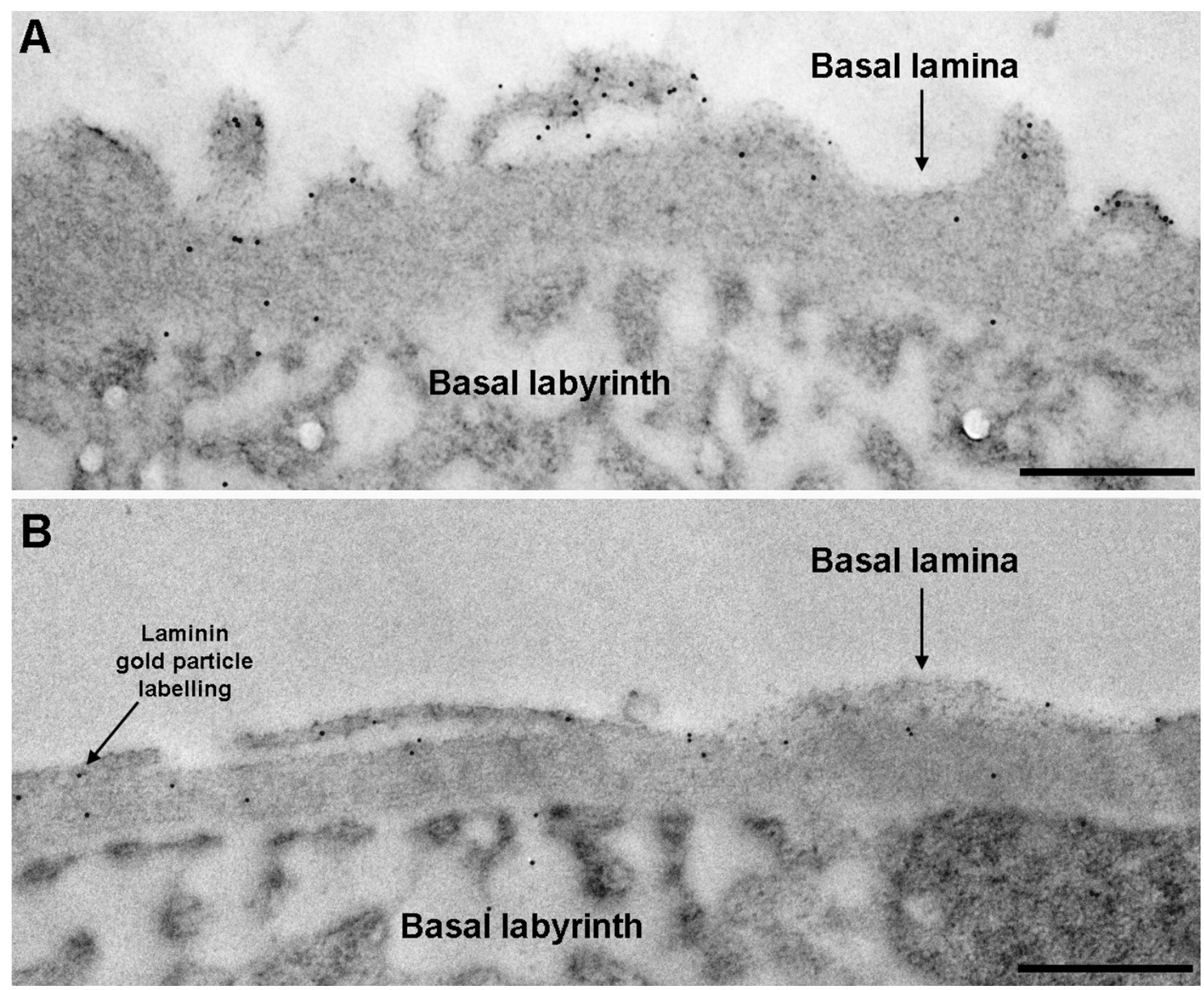

Figure I

Transmission electron micrographs of immunogold-labelled $P$. textbfberghei-infected and non-infected An.

stephensi midguts demonstrating the presence of laminin in the basal lamina. Basal lamina surrounding the midgut epithelium of An. stephensi mosquitoes $(36,000 \times$; scale bar $=500 \mathrm{~nm})$. The distribution and density of laminin labelling $(\mathrm{I}: 4000$, $10 \mathrm{~nm}$ gold particles) is similar in both the A) uninfected and B) infected midguts.

cases, laminin labelling of the midgut lumen was not significantly different from labelling in the resin. Importantly, no significant differences were detected in the density of labelling of the BL between the infected and uninfected midguts (Dunn's Test: $\mathrm{Q}_{(7)}=0.05, P>0.5$ ).

Laminin was found to be present within the midgut epithelial cells (Figure 5). The density of laminin labelling in the uninfected midgut cells was significantly higher than in the resin $\left(Q_{(3)}=2.73, P<0.05\right)$, and was not significantly different from the density of labelling in the $\mathrm{BL}$ $\left(Q_{(3)}=2.15, P>0.2\right)$. In midgut epithelium from infected mosquitoes the density of labelling was significantly higher in the $\mathrm{BL}$ than in the resin, $\left(\mathrm{Q}_{(3)}=5.03, P<0.001\right)$, however, there was no significant difference between labelling in the midgut epithelium and $\operatorname{resin}\left(\mathrm{Q}_{(3)}=1.36\right.$, $P>0.05)$.

Gold particles were observed in clusters, particularly in the apical region of the cells, adjacent to the midgut lumen. This area contains vesicles, secretory organelles such as the endoplasmic reticulum and the Golgi complex, as well as mitochondria $[49,50]$. Gold particle clusters appeared to be associated with vesicles (Figure 5) leading to a more detailed analysis of laminin distribution within the midgut epithelial cells (see Methods). In some 


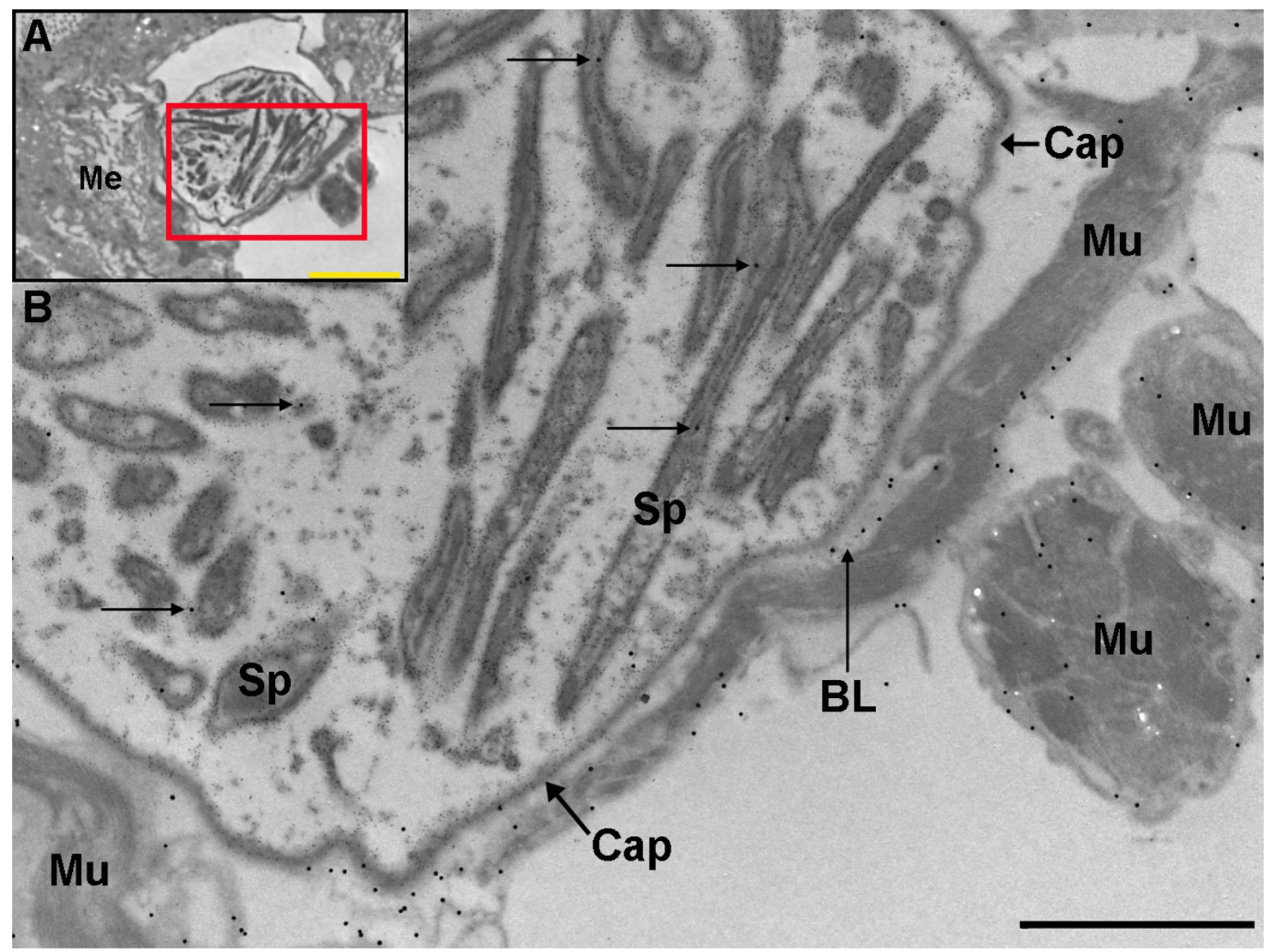

Figure 2

Transmission electron micrograph of immunogold labelling for laminin in a P. berghei oocyst I4 days postinfection. A) Oocyst underneath the basal lamina $(5,000 \times$; scale bar $=5 \mu \mathrm{m})$. B) Higher magnification image of boxed area of A ( $12,000 \times$; scale bar $=2 \mu \mathrm{m})$. Laminin labelling ( $30 \mathrm{~nm}$ gold particles) is found close to the membranes of, or within, developing sporozoites (arrows). Laminin is also present on basal lamina around the midgut and individual muscles blocks. Me $=$ midgut epithelium, $\mathrm{BL}=$ basal lamina, $\mathrm{Sp}=$ sporozoites, Cap = capsule, $\mathrm{Mu}=$ muscle.

sections parts of the secretory machinery could be distinguished, however, as LR white resin embedding does not allow for good preservation of membranes, localisation of gold particles within the ER or other organelles could not be reliably ascertained. Thus, the density of gold particle labelling in vesicles, mitochondria, cytoplasm, microvilli, and midgut lumen was calculated. Significantly more gold particles were associated with vesicles than any of the other structures for the infected midgut cells (ANOVA: $\mathrm{F}_{(4)}$ $=16.30, P<0.001$ ). Labelling of the vesicles in uninfected midgut cells was significantly higher than for any other cellular profiles (ANOVA: $\mathrm{F}_{(4)}=25.79, P<0.001$ ). Finally, there was a significant effect of infection, with laminin labelling higher in midgut cells from the infected mos- quito sections than those from the uninfected ones (GLM: $\left.\mathrm{F}_{(4,1)}=6.08, P=0.016\right)$.

\section{Laminin incorporation into the oocyst capsule}

Eleven oocysts were examined in the infected midgut sections and, where possible, 10 images were collected using a stratified random sampling method. Ninety three images were obtained, from which an analysis of the distribution of gold particles within the oocyst capsules was performed to determine whether the labelling observed reflected an incorporation of laminin into the capsule. The density of laminin labelling in the oocyst capsule was only 2-fold lower than in the BL of both infected and noninfected midgut sections (Table 1 ) and significantly more 


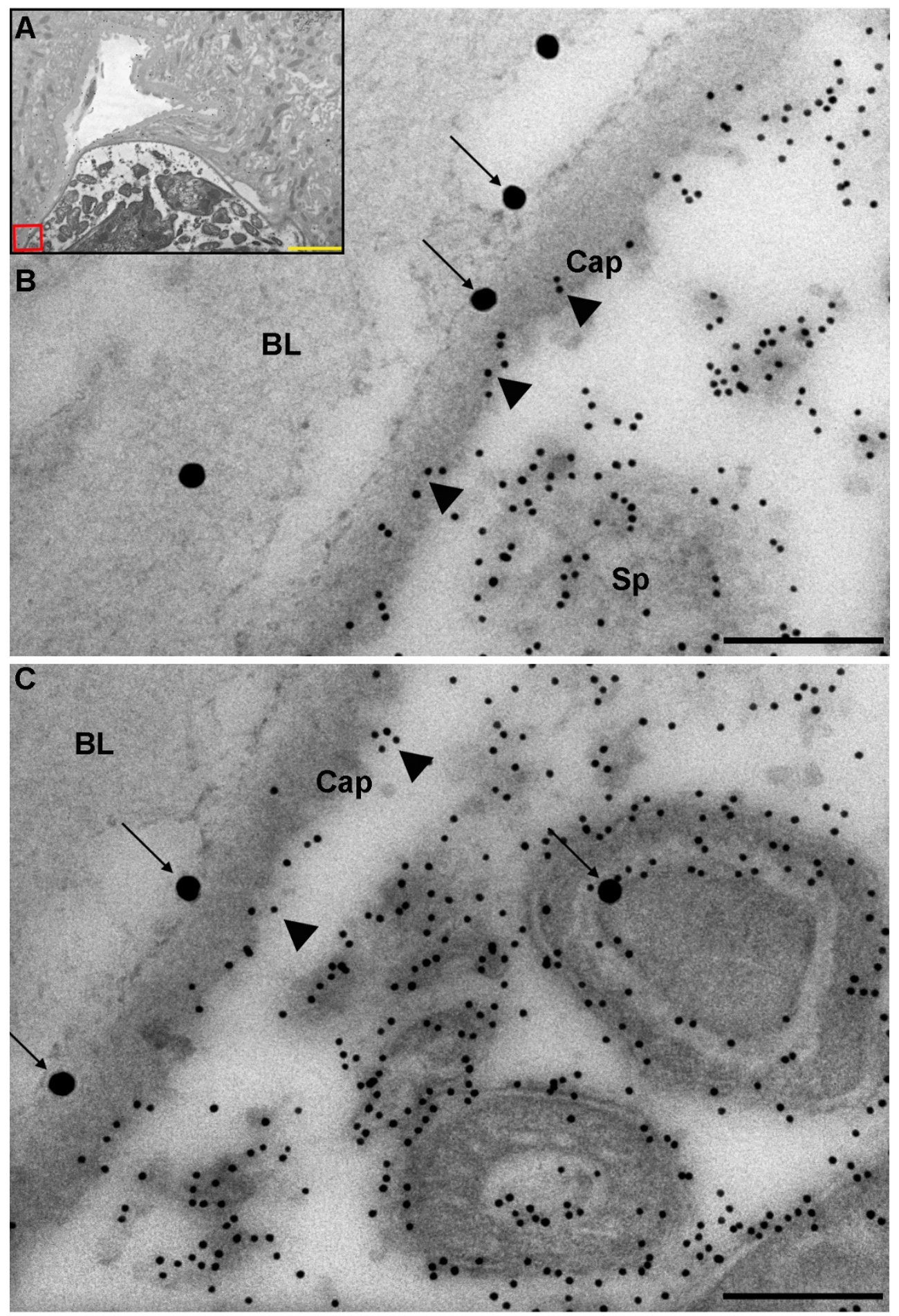

Figure 3

Transmission electron micrograph showing the localisation of An. stephensi laminin and $P$. berghei circumsporozoite protein $I 4$ days post-infection. A) The inset shows the position of the oocyst in the midgut $(10,000 \times$; scale bar $=$ $2 \mu \mathrm{m})$. B) Boxed area shown in A (I20,000 x; scale bar $=200 \mathrm{~nm})$. C) Additional area of the same 00 cyst (I20,000 x; scale bar $=200 \mathrm{~nm})$. Laminin $(1: 400)=30 \mathrm{~nm}$ gold particles (arrows), CSP $(1: 1000)=10 \mathrm{~nm}$ gold particles (arrowheads). Note the presence of labelling for laminin within the sporozoite and on the outer surface of the capsule. $\mathrm{BL}=$ basal lamina, $\mathrm{Sp}=\mathrm{sporozoites,}$ Cap = capsule. 


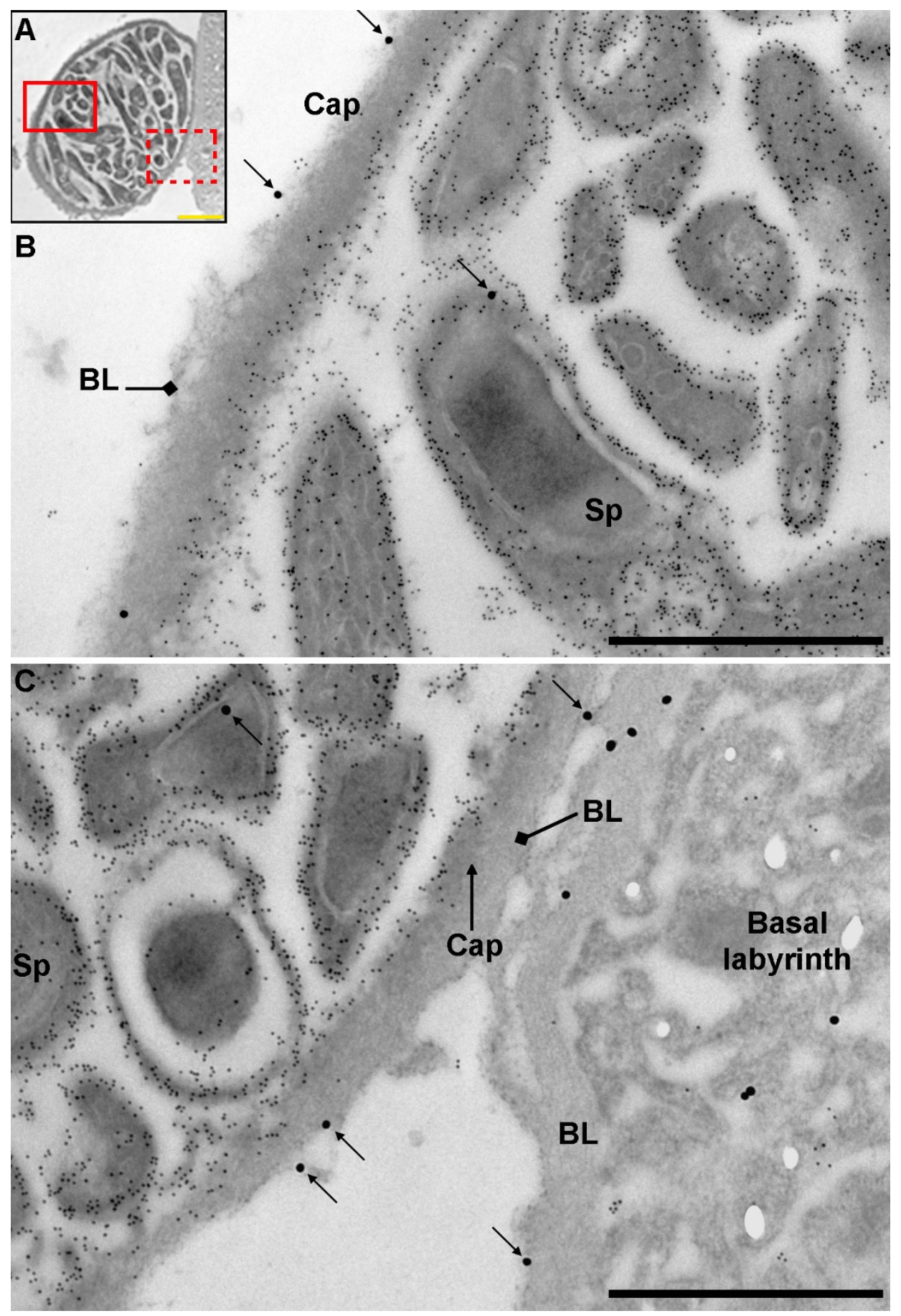

Figure 4

Transmission electron micrograph showing laminin and circumsporozoite protein distribution in $P$. berghei oocysts 14 days post-infection. A) Oocyst on the edge of the midgut epithelium $(12,000 \times$; scale bar $=2 \mu \mathrm{m})$. B boxed area with solid line, C) boxed area with dotted line $(40,000 \times$; scale bar $=1 \mu \mathrm{m})$. The oocyst capsule appears darker than the layer of basal lamina coating it. Remnants of basal lamina are seen on the edge of the oocyst facing the haemocoel (B) and a thicker layer is seen adjacent to the basal labyrinth of the midgut epithelium (C) (diamond arrows). The majority of $30 \mathrm{~nm}$ gold particles indicating laminin labelling ( $1: 800)$ (arrows) are found on the outer surface of the oocyst capsule. Note that some laminin labelling is also found in association with developing sporozoites The $10 \mathrm{~nm}$ gold particles correspond to circumsporozoite protein labelling ( $1: 4000) . \mathrm{BL}=$ basal lamina, Cap $=$ capsule, $\mathrm{Sp}=$ sporozoite. 
Table I: Density of laminin labelling in the capsule of $P$. berghei oocysts.

\begin{tabular}{|c|c|c|}
\hline & $\begin{array}{l}\text { Infected Midgut } \\
\left(\text { mean density/ } / \mathrm{m}^{2}\right)\end{array}$ & $\begin{array}{l}\text { Uninfected Midgut } \\
\left(\text { mean density/ } \mu \mathrm{m}^{2}\right)\end{array}$ \\
\hline P. berghei oocyst capsule & $7.91( \pm 0.82)^{\mathrm{a}}$ & $N / A$ \\
\hline P. berghei oocyst minus capsule* & $1.35( \pm 0.11)^{b}$ & N/A \\
\hline Basal lamina & $14.00( \pm 1.36)^{\mathrm{a}}$ & $13.98( \pm 1.71)^{x}$ \\
\hline Midgut Epithelium $\neq$ & $\mathrm{I} .02( \pm 0.39)^{\mathrm{b}}$ & $2.03( \pm 0.80)^{x}$ \\
\hline Midgut lumen & $0.89( \pm 0.19)^{\mathrm{b}}$ & $0.18( \pm 0.05)^{y}$ \\
\hline Resin & $0.30( \pm 0.07)^{\mathrm{b}}$ & $0.17( \pm 0.04)^{y}$ \\
\hline
\end{tabular}

There was significantly more labelling of laminin in the oocyst capsule and the midgut basal lamina than the control areas or $P$. berghei oocysts minus capsule. Values in brackets $=$ standard error of the mean. Infected midgut: a indicates a significant difference from control areas denoted by ${ }^{b}$. Uninfected midgut: $x$ indicates a significant difference from control area denoted by $y$. *Laminin distribution was analysed within whole oocysts (minus capsule) without any distinction made between sporozoites, cytoplasm or subcapsular space. ${ }^{\neq}$Analysis was performed on whole cells with no distinction between cytoplasm and organelles. In later analyses, laminin distribution in various organelles was compared to distribution in the midgut lumen.

labelling was observed in or around the capsule than in the resin $\left(\mathrm{Q}_{(3)}=4.33, P<0.001\right)$ and gut lumen $(P<$ $0.05)$. Only sixty percent of the gold particles associated with the oocyst capsule were localised on the exterior surface of the capsule (Figure 6), indicating that, although laminin was primarily bound to the outer surface of the oocyst capsule, a considerable amount had been incorporated into the capsule (Figure 7). To confirm this, a comparison was made with an equivalent area of midgut lumen. The density of gold particles within the oocyst capsule was significantly higher than in the midgut lumen (Chi-square: $\left.\chi_{(1)}^{2} 48.6, P<0.001\right)$ suggesting that laminin is indeed incorporated into the capsule.

\section{Laminin labelling associated with sporozoites}

Even though labelling of laminin within oocysts as a whole was not significantly different from control areas (Table 1, oocysts minus capsule) an examination of the sections suggested a systematic association of laminin gold particle-labelling with sporozoites (Figure 8). In order to assess whether this labelling pattern was real, or a visual artefact due to non-specific binding, gold particle distribution was analysed so that a distinction was made between gold particles associated with developing sporozoites and those in the oocysts' cytoplasm again using 10 nm particles, (see Methods for further details). A significantly higher proportion of gold particles was found to be localised in developing sporozoites than in the oocyst cytoplasm ( $t$-test: $t_{(9)}=3.54, P=0.003$ ) indicating a specific association of laminin with sporozoites within oocysts. These observations may reflect an actual binding of the antibodies to laminin located within sporozoites, or cross-reactivity with sporozoite protein(s). The former would imply that laminin is internalised into the oocyst and then binds to sporozoite molecules, the latter, that one or more sporozoite proteins contain laminin-like domains. Cross reactivity with circumsporozoite protein (CSP) was considered as this protein has been reported to be localised on the inner surface of the capsule and on sporozoites, and indeed our observations confirm this. However, the distribution of laminin was not consistent with the localisation of CSP on the inner surface of the capsule.

To determine if cross-reactivity may have occurred with any sporozoite stage proteins, a sequence similarity search against the Plasmodium genome was performed using $D$. melanogaster laminin sequences. The annotated sequences with the highest homology were the recently characterised cysteine repeat modular proteins (e.g. PbCRMP2, E-value $=4.0 e-06,36 \%$ similarity). They are predicted to be expressed on the parasite surface and to contain a single EGF-like domain proximal to a transmembrane domain [51]. Four distinct proteins have been characterised in $P$. falciparum, all of which are expressed in sporozoites (salivary gland: PfCRMP1 and 2; oocyst sporozoites: PfCRMP3 and 4) [51]. PfCRMP2, in particular, is expressed in sporozoites emerging from oocysts [51]. In addition, Thompson et al. [51] determined the expression of the P. berghei homologues and found that PbCRMP1 is expressed in young oocysts and sporulating oocysts, whereas PbCRMP2 is expressed in sporulating oocysts and sporozoites.

\section{Discussion}

This study has clearly demonstrated that laminin, a major component of the midgut $\mathrm{BL}$, coats the external surface of the oocyst capsule, which is clearly distinct from the $\mathrm{BL}$, and is also incorporated into the capsule. Although the incorporation of other BL components into the capsule was not investigated here, it is conceivable that collagen IV and other molecules could also form a coating over the oocyst capsule, adding to the disguise [10].

The presence of laminin labelling within oocysts, and specifically associated with sporozoites, was unexpected. We believe it was synthesised by the mosquito, not the parasite. The oocyst capsule is permeable to amino acids (Van- 


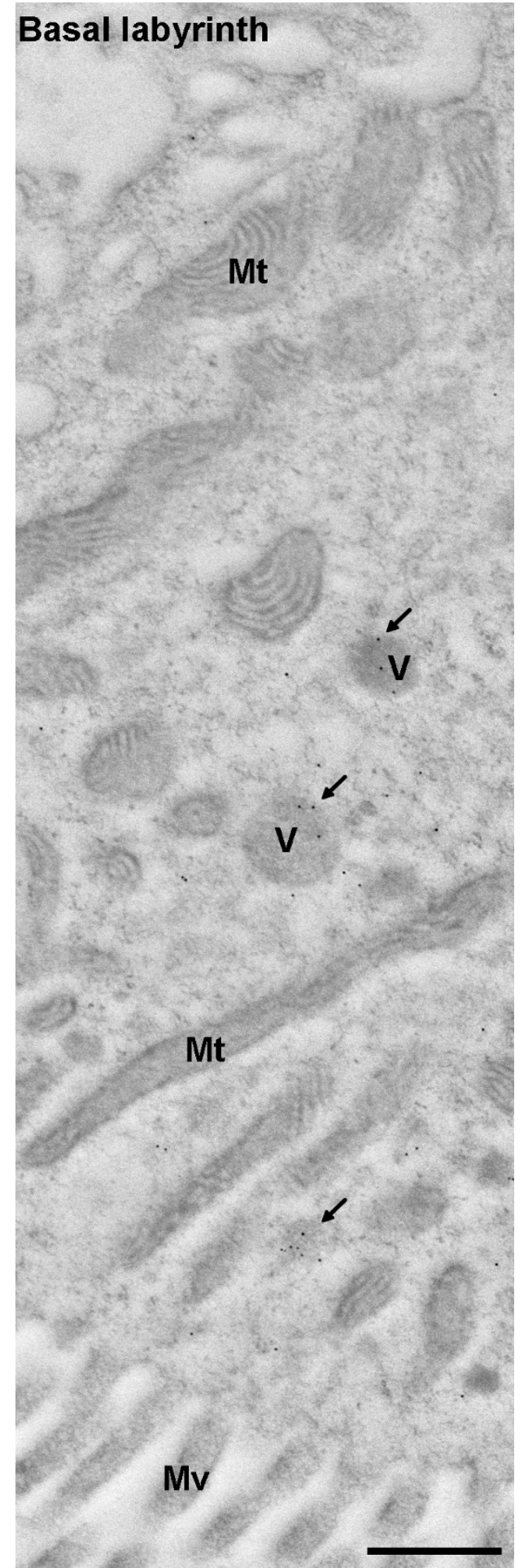

\section{Figure 5}

Laminin distribution in midgut epithelial cells. A section spanning the midgut epithelium from the basal labyrinth to the microvilli. Clusters of laminin labelling ( I:4000) can be seen in vesicles (arrows) $(36,000 \times$; scale bar $=500 \mathrm{~nm})$. Mv $=$ microvilli, $\mathrm{Mt}=$ mitochondria, $\mathrm{V}=$ vesicles . derberg and Rozeboom, as cited in [12]) and it is probable that macromolecules such as laminin also pass through it. The mechanism by which laminin would then be internalised into the oocyst, which would require it to pass through the oocyst plasma membrane, is unclear. The parasitic protozoans Tritrichomonas foetus and Trichomonas vaginalis have been reported to ingest latex or micron beads coated with laminin by pinocytosis [52,53]. It is possible that Plasmodium could have a similar mechanism for laminin uptake.

Since single cell organisms are not believed to be able to synthesise BLs or the complex proteins that constitute them [54] we must also consider whether the anti-laminin antibodies used were binding non-specifically to other proteins. The major ookinete surface proteins of Plasmodium, P25 and P28, contain EGF-like repeats $[55,56]$ which are characteristic of laminins. However, labelling of the ookinete surface was not observed with the antibodies used in this study (data not shown), a finding also reported by Arrighi et al. [25] using anti-mouse-laminin antibodies. Therefore if this motif were recognised, it would not, in itself, be sufficient for labelling by these antibodies. This suggests that cross-reactivity with these proteins does not occur. With regards to other proteins expressed in the oocysts, the cysteine rich modular proteins (PxCRMP) were also considered as candidates for cross-reactivity, however, we think this is unlikely as these proteins only contain a single EGF-like domain, unlike P28, P25, and laminin [51]. It remains to be confirmed whether the gold labelling was indeed specific for laminin or whether anti-laminin antibodies are also binding to Plasmodium proteins.

Within the midgut it has been shown that laminin is upregulated after a blood meal and the BL itself thickens post-blood feeding $[19,25,57]$. A number of morphological changes rapidly occur within the midgut epithelium following a blood meal, including the accumulation of mitochondria and secretory vesicles in proximity to the brush border, the unfolding of the basal labyrinth (thus increasing surface area) and an increase in protein abundance $[50,58]$. In addition, it has been reported that collagen IV expression shows a 2-fold increase during oocyst development when compared to expression levels following an uninfected blood feed. Gare et al. [19] speculated that the upregulation of collagen IV and possibly other BL proteins during infections are akin to a wound healing response in infected mosquitoes. However, it has been reported that fourteen days post-blood feeding (the time of this study) the midgut epithelium and BL have recovered from the stresses induced by the presence of a blood meal $[19,50,58]$. Furthermore, the development of a new BL around the midgut epithelium ceases between 10-15 days post-infection when repair has been achieved [19]. 


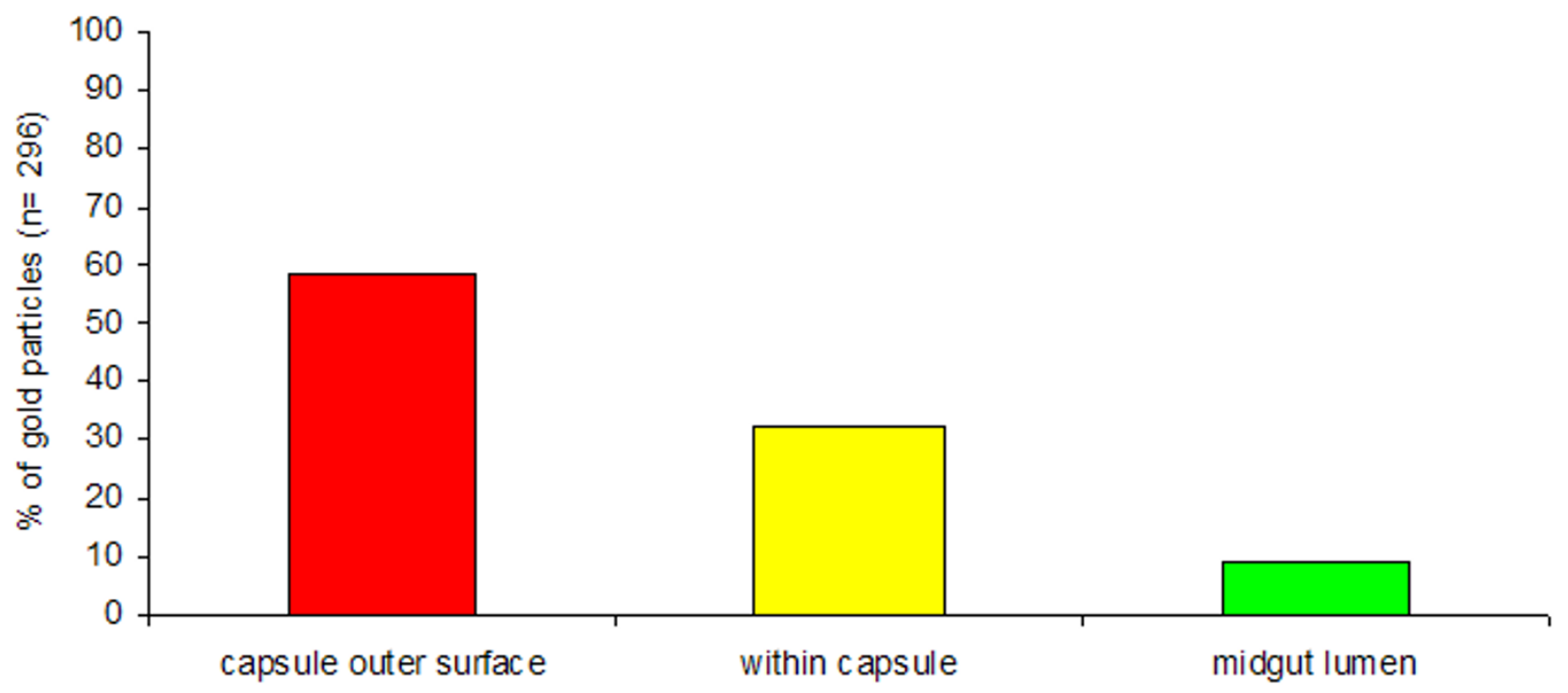

\section{Figure 6}

Distribution of laminin in P. berghei oocyst capsules. Ninety three areas of capsule from II P. berghei oocysts were analysed to determine the precise location of laminin by immunogold labelling using anti-D. melanogaster laminin antibodies directed against the $\beta$ and $\gamma$ chains and detected with a $10 \mathrm{~nm}$ gold-conjugated secondary antibody. The percentage distribution of gold particles $(n=296)$ situated either on the outer surface of the capsule, within the capsule or and equivalent are of midgut lumen was calculated.

In this study, the thickness of the BL and the density of laminin therein did not differ between infected and uninfected An. stephensi fourteen days post-blood feeding.

Laminin was detected within the midgut epithelial cells. It was concentrated in vesicles that were mostly located at the apical end of the cells, in areas containing large numbers of mitochondria. Laminin labelling in the uninfected An. stephensi midgut epithelial cells was significantly higher than in the resin or midgut lumen, suggesting that laminin may be synthesised by midgut epithelial cells and exported via vesicles to the BL. Although our observations of laminin distribution in the midgut epithelium are based on sections from single infected and uninfected midguts and must therefore be interpreted with caution, studies examining the expression of BL components have shown that both collagen IV and laminin are expressed in the midgut epithelium $[19,20,25]$; lending support to our findings. Endocytosis of laminin has been reported to occur in mammals (a process associated with the turnover of the extracellular matrix during wound healing and growth [59]); a similar process could also be occurring here.

The BL has been shown to be an important indicator of 'self' in insects [60]. Parasites able to bind BL components to their surface could appear as 'self' and thus evade recognition by the mosquito's immune system $[10,20,29,30,35,36]$. For example, recombinant $P$. gallinaceum P28, mouse laminin, and Drosophila-conditioned cell culture medium (known to contain BL components) all contribute to a reduction in the melanisation of Sephadex beads by Ae. aegypti [40]. Furthermore, P. berghei ookinetes are coated by laminin prior to the completion of their passage through the midgut of An. gambiae [25]. It is likely that this coating will assist with evasion of the immune system. Adini and Warburg [10] proposed that mosquito BL proteins were incorporated into the capsule of Plasmodium oocysts and speculated that this would enable them to be masked from the immune response of the vector. Oocysts produced in vitro typically do not form a distinct capsule ([31,32,61] (personal observations), suggesting an essential role for mosquito-derived proteins in the formation of this structure. Furthermore, it has recently been shown that PbCAP380-disrupted parasites, that are not able to form a capsule, do not survive in the mosquito midgut [8]. The authors speculated that this protein could be implicated in the incorporation of mosquito molecules into the capsule; a key interaction that, when interrupted, results in parasites that are unable to mask themselves from the mosquito's immune system [8]. 


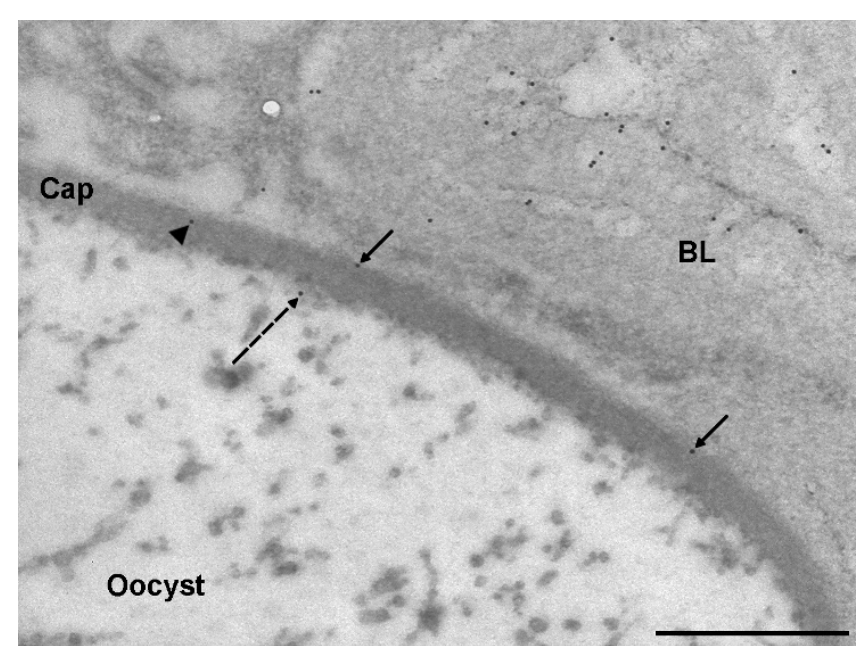

\section{Figure 7}

Localisation of laminin in the capsule of $P$. berghei oocysts. Sections of $P$. berghei- infected An. stephensi midguts were probed with anti- $D$. melanogaster laminin-I antibodies ( $1: 4000)$ followed by $10 \mathrm{~nm}$ gold particle-conjugated secondary antibodies. Laminin is present on the outer surface of the capsule (arrows), within the capsule (arrowhead), and on the inner surface of the capsule (dashed arrow) $(60,000 \times$; scale bar $=500 \mathrm{~nm})$. Cap = capsule, $\mathrm{BL}=$ basal lamina.

At 14 days post-infection, most of the oocysts in this study were not surrounded by a thick and continuous BL on the haemocoel side. Currently, the widely accepted model to explain the observation that oocysts are coated in BL com-

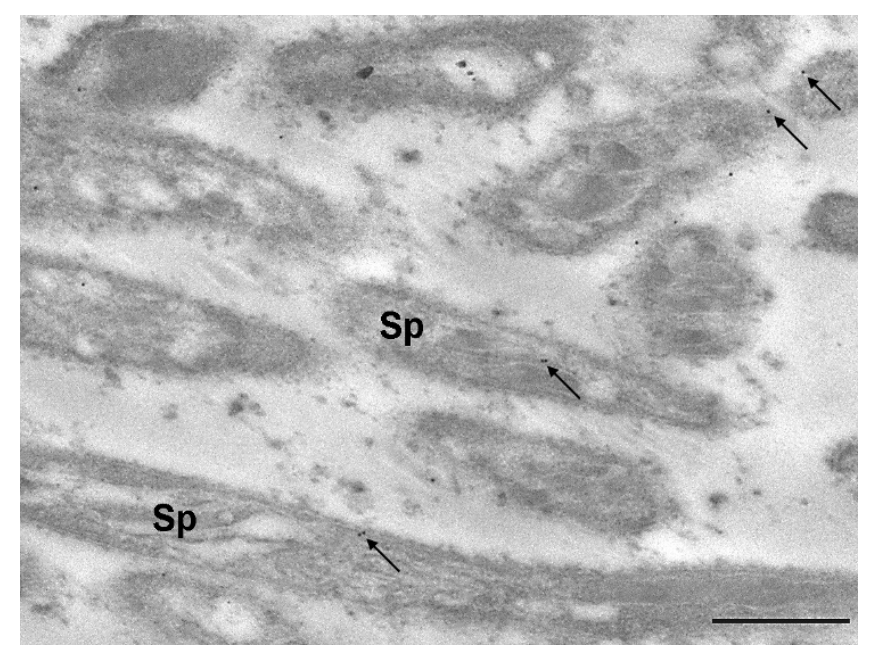

\section{Figure 8}

Localisation of laminin in a P. berghei oocyst. Sections of $P$. berghei- infected An. stephensi midguts were probed with anti- D. melanogaster laminin-I antibodies ( I:4000). Labelling was often observed within or near developing sporozoites (arrows) $(36,000 \times$; scale bars $=500 \mathrm{~nm}) . \mathrm{Sp}=$ sporozoites. ponents is that the extracellular matrix is secreted by haemocytes [62]. If so, then this secretion could be related to their function as immune competent cells as it has been reported that the melanotic encapsulation of pathogens is terminated by the addition of basement membrane-like layer [63]. However, one must question why, if haemocytes are responsible for producing the midgut $\mathrm{BL}$, new $\mathrm{BL}$ is not continuously being laid down as the oocysts grow and expand. If the formation of the $\mathrm{BL}$ is essentially dependent upon synthesis by midgut epithelial cells, one would expect the BL to be present as a thicker layer on the parts of the oocyst adjacent to the basal labyrinth, as was frequently observed in this study and has previously been reported [19]. The observations presented here, and those of Arrighi et al. [25] and Gare et al. [19] demonstrating that laminin and collagen IV, respectively, are transcribed in the midgut epithelium, strongly suggest a role for midgut epithelial cells in the production of the BL. These two potential sources of BL need not, however, be mutually exclusive. BLs have important biological functions and it is possible that the midgut epithelium and haemocytes both contribute to their synthesis.

Our observations have led us to propose the following model (outlined in Figure 9) for further investigation. Laminin, synthesised by midgut epithelial cells, adheres to and coats ookinetes during their passage towards the $\mathrm{BL}$, as proposed for $\beta$ integrin coating [64]. Upon contact with the $\mathrm{BL}$, ookinetes stop migrating, perhaps because of an inhibitory role of laminin on locomotion, or perhaps because ookinetes bind to the $\mathrm{BL}$ and can no longer glide. Transformation is initiated here and nutrients circulating in the haemolymph are probably required for the complete transformation of ookinetes into oocysts [5]. As oocysts grow, laminin and perhaps other BL components continue to be secreted by the epithelial cells and both coat and are incorporated into the oocyst capsule. Whether the observed incorporation of laminin into the oocyst capsule is reflective of laminin forming an integral part of the capsule, or just passing though it, remains to be elucidated.

\section{Conclusion}

Here we show by semi-quantitative immunogold labelling that, at 14 days post- infection, laminin coats and is incorporated into the capsule of $P$. berghei oocysts. Immunogold labelling for laminin was also observed in sporozoites within maturing oocysts and we suggest a putative role for laminin in protecting both the oocyst and sporozoite from the mosquito defence system. In addition, we show that laminin is associated with vesicles present in the midgut epithelial cells. This observation has led us to propose that ookinetes traversing the midgut may become coated in laminin, and possibly other BL components that 


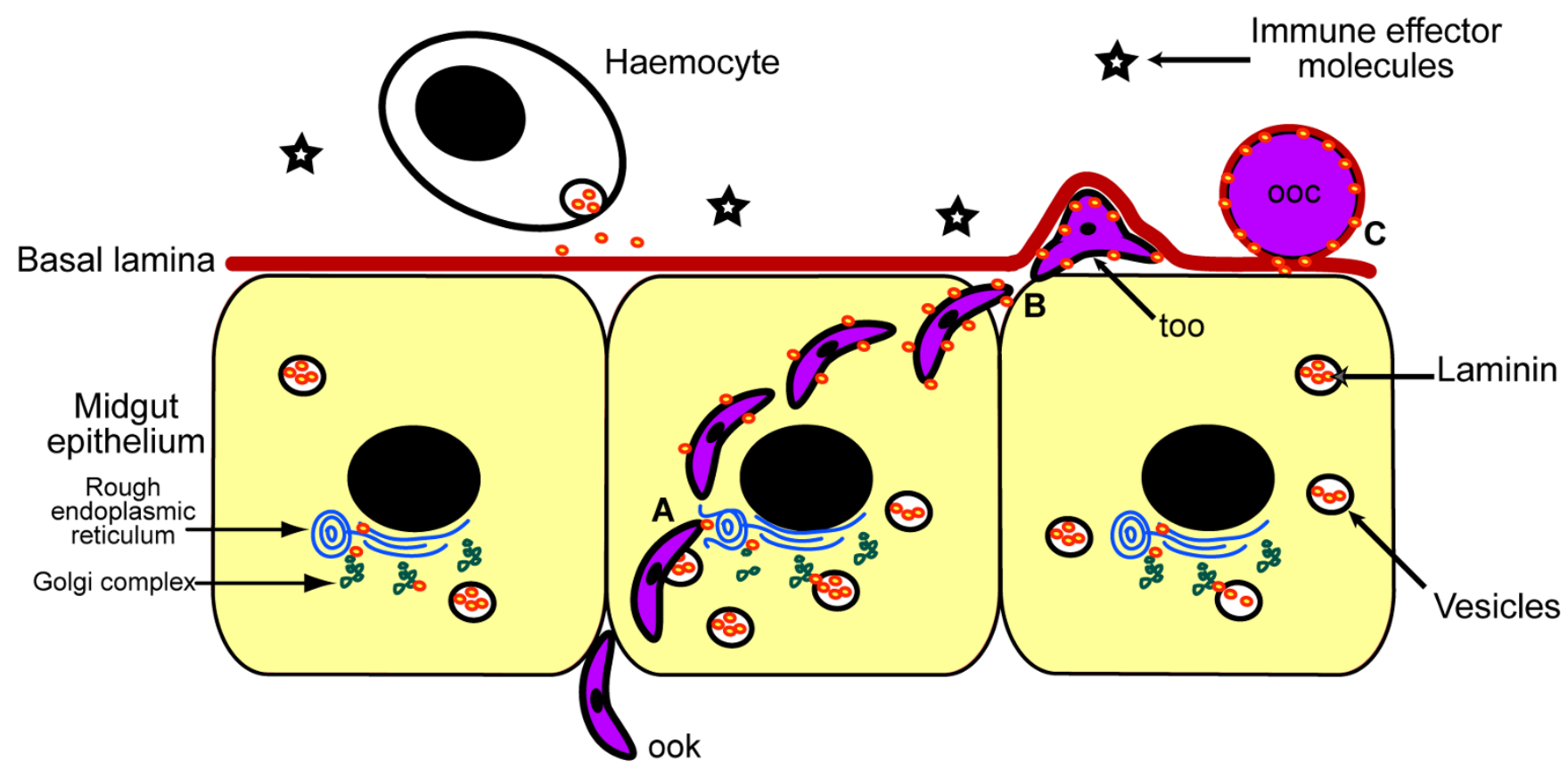

Figure 9

Proposed model of interaction between $\boldsymbol{P}$. berghei sporogonic stages and An. stephensi laminin. A) Ookinetes (ook) are coated with laminin produced by midgut epithelial cells when they migrate through these cells as they disrupt membranes of the secretory machinery during migration. B) This enables them to mask themselves from the immune system when they reach the basal lamina and begin transformation via a took stage (too). C) The basal lamina is stretched by the developing oocysts (০oc) and laminin is replaced beneath the oocysts by production in the midgut cells. Haemocytes may also contribute to the midgut $B L$.

would enable ookinetes to evade the vector's immune system as they emerge from the epithelial cells.

\section{Methods}

Mosquito infections

Adult female An. stephensi Liston (Dubai Strain) mosquitoes were allowed to blood feed on a male CD mouse infected with P. berghei ANKA ${ }_{\mathrm{CON}}[65]$ for $35 \mathrm{~min}$. A control blood feed on an uninfected CD male mouse was performed in parallel with mosquitoes from the same generation. After blood feeding, mosquitoes were transferred to a $19^{\circ} \mathrm{C}$ incubator and maintained on a $4 \%$ glucose solution containing $0.05 \%$ para-aminobenzoic acid, $200 \mathrm{U} / \mathrm{L}$ penicillin, and $200 \mu \mathrm{g} / \mathrm{L}$ streptomycin. Unfed mosquitoes were removed from each treatment cage $24 \mathrm{~h}$ post-blood feeding. Experiments were performed using approved protocols in accordance with the UK Animals (Scientific Procedures) Act 1986 under licence from the UK Home Office.

\section{Fixation and embedding}

P. berghei $\mathrm{GFP}_{\mathrm{CON}}$-infected An. stephensi midguts were monitored 14 days post-infection by fluorescence microscopy. Three infected and five uninfected midguts were fixed in $4 \%$ paraformaldehyde containing $0.1 \%$ glutaral- dehyde in $0.1 \mathrm{M}$ phosphate buffer (PB) for $2 \mathrm{~h}$ on a rotator. The samples were washed three times for $5 \mathrm{~min}$ in 0.1 M PB and dehydrated in a graded ethanolic series. The midguts were then infiltrated with LR-White Hard Grade Acrylic Resin (Agar Scientific) for $2 \mathrm{~h}$ on a rotator. Samples were infiltrated twice more with fresh LR-white resin, and a further infiltration step was performed overnight. Following an additional 2 resin changes, samples were transferred to capped gelatine beam capsules and polymerised for $24 \mathrm{~h}$ at $50^{\circ} \mathrm{C}$. Using a Leica Ultracut UCT Ultramicrotome $100 \mathrm{~nm}$ ultrathin sections were taken transversally through an infected and uninfected midgut and collected onto 200 mesh thin bar nickel grids (Product code: G2002N, Agar Scientific).

\section{Antibodies and specificity controls}

Laminin was detected in An. stephensi midgut sections using affinity purified rabbit polyclonal antibodies raised against the $\beta$ and $\gamma$ chains, respectively, of laminin secreted by D. melanogaster Kc167 cell cultures [44] at $1: 800$ or $1: 4000$ dilutions. Some sections were also labelled with a P. berghei circumsporozoite protein (CSP) mouse monoclonal antibody (3D11) at 1:100 or 1:4000 depending on the secondary antibody gold particle diam- 
eter. Labelling controls included a rabbit IgG antibody (Sigma) or omission of the primary antibody.

\section{Post-embedded immunogold labelling}

Labelling was performed in a humid chamber by immersing grids in a series of reagents. Grids labelled for the quantitative analysis were immersed in the same drop of each reagent to ensure that samples (infected and uninfected midguts) were labelled in the same conditions. Prior to labelling, grids were placed in $40 \mu \mathrm{l}$ of $0.05 \mathrm{M}$ Tris buffered saline, (TBS) pH7.4, for 5 min and blocked for $30 \mathrm{~min}$ in $20 \%$ goat serum (Harlan Sera Lab) in TBS. Grids were then incubated overnight at $4{ }^{\circ} \mathrm{C}$ in a mixture of both primary antibodies (CSP 1:1000 or 1:4000; laminin 1:400 or $1: 800$ ) diluted in $1 \%$ goat serum in TBS (GS-TBS). Following three ten minute immersions in TBS, samples were blocked for 15 min with 20\% GS-TBS. Grids were immersed for $1 \mathrm{~h}$ at room temperature with anti-mouse IgG-10 nm gold-conjugated antibody (British Biocell) mixed with anti-rabbit IgG-30 nm gold-conjugated antibody, each diluted 1:20 in 1\% GS-TBS. Semi-quantitative analyses were performed by labelling only with laminin (1:4000) followed by an anti-rabbit IgG-10 nm gold-conjugated antibody. Grids were stained with 2\% aqueous uranyl acetate for $20 \mathrm{~min}$ and dried prior to examination with a JEOL 1230 transmission electron microscope (TEM) and/or a JEOL 100 CXII TEM. Images were acquired with a MegaView III digital camera (Soft Imaging Systems) using iTEM software analysis (Soft Imaging Systems). Several sections (3-5) were observed for all experiments.

\section{Semi-quantitative analysis of laminin labelling of P. berghei oocysts and An. stephensi midguts}

The density of laminin labelling (gold particles $/ \mu \mathrm{m}^{2}$ ) was determined in portions of oocyst capsule, oocysts, the BL, midgut epithelium, gut lumen, and resin for both the infected and uninfected midguts. Images were acquired at a fixed magnification of either $60,000 \times($ JEOL 1230) or $36,000$ and 58,000 $\times$ (JEOL $100 \mathrm{CXII})$.

Areas of oocyst capsule used for the analysis were selected using a stratified random sampling method. Briefly, the selection of oocysts was not random (all were sampled) but for each oocyst the initial area chosen for counts was selected randomly by reducing the magnification to a level where the gold particles were indiscernible, images were then acquired for every other field of view around the oocyst and 93 images were acquired in total. For all other areas of interest, namely: oocysts, $\mathrm{BL}$, midgut epithelium, gut lumen, and resin, areas were selected at random and 10 images were acquired per region of interest.

To investigate if an association existed between laminin labelling and developing sporozoites, which appeared to be more densely labelled than oocyst cytoplasm, the data were analysed following a method described by Mahendrasingam and colleagues [66]. Briefly, an overlay containing regularly spaced lines was placed onto the images using the GNU Image Manipulation Software http:// www.gimp.org. The number of points touching and/or lying within sporozoites and cytoplasm was counted to estimate the proportion of oocyst occupied by each of these regions, and the number of gold particles falling into each region was counted. Gold particles were only deemed to be associated with sporozoites if they were located within them or on the membrane. When gold particles were located within 1 particle diameter of each other, a count of only 1 was given, as it is likely that those particles were binding to the same site. The total area of oocyst for each image was measured using iTEM analySIS software (Soft Imaging Systems) and the proportion of the area occupied by sporozoites and cytoplasm was determined. Using these data, the density of gold labelling (number of gold particles $/ \mu \mathrm{m}^{2}$ ) was calculated.

In order to investigate whether laminin present in midgut epithelial cells, was associated with any cellular structures (e.g. vesicles) 10 images of midgut epithelium were acquired for each midgut (infected and uninfected). Preliminary observations suggested a denser pattern of labelling on the lumenal side of the midgut, thus images were acquired at random within this region and analysed as described above [66]. The density of immunogold labelling within vesicles, mitochondria, microvilli, gut lumen and cytoplasm was calculated.

\section{Laminin-like sequences in Plasmodium}

To determine whether cross-reactivity could have occurred with proteins from any stage of Plasmodium, sequences for the Drosophila laminin $\alpha 1$ [GenBank: AAA28662], $\beta$ [GenBank: AAD19752], and $\gamma$ [GenBank: AAA28664] chains were retrieved from the National Center for Biotechnology Information (National Library of Medicine and National Institutes of Health) protein sequence database using Geneious Pro version 2.5.4 (Biomatters Ltd, [67]). These sequences were used to search for laminin-like sequences by using the NCBI Basic Local Alignment Search Tool (BLAST) against the apicomplexan database.

\section{Statistical analysis}

A comparison of the density of laminin labelling in the oocyst capsule and BL with control areas such as resin and gut lumen was analysed with the non-parametric KruskalWallis test in conjunction with Dunn's test for multiple comparisons [68]. The distribution of gold particles within the capsule, indicative of incorporation, was analysed with a Chi-square goodness of fit test. The density of gold particles in association with sporozoites was ana- 
lysed using a one-tailed 2-sample $t$-test. Finally, the association of laminin with cellular structures within infected and uninfected midgut epithelial cells was analysed on transformed data with a one-way ANOVA and a General Linear Model [68]. Statistical analyses were performed with Minitab ${ }^{\circledast} 15$ (ANOVA, GLM, and Chi-squared) and GraphPad Prism ${ }^{\circledast}$ version 5 (Kruskal-Wallis and Dunn's Test).

\section{Competing interests}

The authors declare that they have no competing interests.

\section{Authors' contributions}

AN performed the mosquito infections and immunogold electron microscopy labelling. KW sectioned the midguts and aided in the acquisition of data. HH conceived of the project and AN and $\mathrm{HH}$ prepared the manuscript.

\section{Acknowledgements}

We thank Y. Kitagawa (Nagoya University, Japan) for providing the antiDrosophila laminin antibodies, A. Underhill for technical assistance, D. Furness for advice on methods for the quantitative analysis of immunogold labelling and A. Polwart for assistance with statistical analyses. Funding for this project was provided by The Wellcome Trust (069128/Z/02/Z and $069162 / Z / 02 / Z)$. We are grateful to them for their support.

\section{References}

I. The global problem at a glance: quick notes on the global problem of malaria [http://malaria.wellcome.ac.uk] doc WTD022247.html]

2. Guyatt HL, Snow RW: The cost of not treating bednets. Trends Parasitol 2002, I 8:12-14

3. Takken W: Do insecticide-treated bednets have an effect on malaria vectors? Trop Med Int Health 2002, 7:1022-1030.

4. Simonetti $A B$ : The biology of malarial parasite in the mosquito- a review. Mem Inst Oswaldo Cruz 1996, 9 I (5):519-54I.

5. Carter V, Nacer A, Underhill BA, Sinden RE, Hurd H: Minimum requirements for ookinete to oocyst transformation in Plasmodium. Int J Parasitol 2007, 37: I 221-I232.

6. Hillyer JF, C B, Vernick KD: Efficiency of salivary gland invasion by malaria sporozoites is controlled by rapid sporozoite destruction in the mosquito haemocoel. Int J Parasitol 2007, 37:673-681.

7. Canning EU, Sinden RE: The organization of the ookinete and observations on nuclear division in oocysts of Plasmodium berghei. Parasitology 1973, 67( I):29-40.

8. Srinivasan $\mathrm{P}$, Fujioka $\mathrm{H}$, Jacobs-Lorena $\mathrm{M}$ : PbCap380, a novel oocyst capsule protein, is essential for malaria parasite survival in the mosquito. Cell Microbiol 2008, 1 0:1304-1312.

9. Baton LA, Ranford-Cartwright LC: Spreading the seeds of million-murdering death: metamorphoses of malaria in the mosquito. Trends Parasitol 2005, 2 I :573-580.

10. Adini A, Warburg A: Interaction of Plasmodium gallinaceum ookinetes and oocysts with extracellular matrix proteins. Parasitology 1999, I I9(Pt 4):331-336.

I I. Terzakis JA, Sprinz H, Ward RA: The transformation of the Plasmodium gallinaceum oocyst in Aedes aegypti mosquitoes. J Cell Biol 1967, 34:3 II-326.

12. Vanderberg JP, Rhodin J, Yoeli M: Electron microscopic and histochemical studies of sporozoite formation in Plasmodium berghei. J Protozool 1967, 14:82-103.

13. Aly AS, Matuschewski K: A malarial cysteine protease is necessary for Plasmodium sporozoite egress from oocysts. J Exp Med 2005, 202:225-230.

14. Mehlhorn H, Peters W, Haberkorn W: The formation of kinets and oocysts in Plasmodium gallinaceum and considerations on phylogenetic ralationships between haemosporidia, piroplasmida and other coccida. Protistologica 1980, I6:135-I54.

15. Adini A, Krugliak M, Ginsburg H, Li L, Lavie L, Warburg A: Transglutaminase in Plasmodium parasites: activity and putative role in oocysts and blood stages. Mol Biochem Parasitol 200I, I17:161-168.

16. Hynes RO, Zhao Q: The evolution of cell adhesion. J Cell Biol 2000, I 50:F89-96.

17. Alberts B, Johnson A, Lewis J, Raff M, Roberts K, Walter P: Molecular Biology of the Cell 4th edition. New York: Garland Science; 2002.

18. Friedrich MV, Schneider M, Timpl R, Baumgartner S: Perlecan domain V of Drosophila melanogaster. Sequence, recombinant analysis and tissue expression. Eur J Biochem 2000, 267:3149-3159.

19. Gare DC, Piertney SB, Billingsley PF: Anopheles gambiae collagen IV genes: cloning, phylogeny and midgut expression associated with blood feeding and Plasmodium infection. Int J Parasitol 2003, 33:681-690.

20. Vlachou D, Lycett G, Siden-Kiamos I, Blass C, Sinden RE, Louis C: Anopheles gambiae laminin interacts with the P25 surface protein of Plasmodium berghei ookinetes. Mol Biochem Parasitol 200I, I I 2:229-237.

21. Fessler JH, Fessler LI: Drosophila extracellular matrix. Ann Rev Cell Biol 1989, 5:309-339.

22. Lackie AM: Haemocyte behavior. J Cell Sci 1983, 63:181-190.

23. Nardi JB, Gao C, Kanost MR: The extracellular matrix protein lacunin is expressed by a subset of hemocytes involved in basal lamina morphogenesis. J Insect Physiol 2001, 47:997-1006.

24. Wigglesworth VB: Secretory activities of plasmatocytes and oenocytoids during the moulting cycle in an insect (Rhodnius). Tissue Cell 1979, I I:69-78.

25. Arrighi RBG, Lycett G, Mahairaki V, Siden-Kiamos I, Louis C: Laminin and the malaria parasite's journey through the mosquito midgut. J Exp Biol 2005, 208:2497-2502.

26. Fessler LI, Campbell AG, Duncan KG, Fessler JH: Drosophila laminin: characterization and localization. I Cell Biol 1987, 105:2383-2391.

27. Whitten JM: Haemocytes and the metamorphosing tissues in Sarcophaga bullata, Drosophila melanogaster and other cyclorrhaphous Diptera. I Insect Physiol 1964, I 0:447-469.

28. Knibiehler B, Mirre C, Cecchini J-P, LeParco Y: Haemocytes accumulate collagen transcripts during Drosophila melanogaster metamorphosis. Roux's Arch Dev Biol 1987, I 96:243-247.

29. Dessens JT, Siden-Kiamos I, Mendoza J, Mahairaki V, Khater E, Vlachou D, Xu XJ, Kafatos FC, Louis C, Dimopoulos G, Sinden RE: SOAP, a novel malaria ookinete protein involved in mosquito midgut invasion and oocyst development. Mol Microbiol 2003, 49:319-329.

30. Mahairaki V, Voyatzi T, Siden-Kiamos I, Louis C: The Anopheles gambiae gammal laminin directly binds the Plasmodium berghei circumsporozoite- and TRAP-related protein (CTRP). Mol Biochem Parasitol 2005, I 40: I 19-I2I

31. Warburg A, Miller LH: Sporogonic development of a malaria parasite in vitro. Science 1992, 255:448-450.

32. Warburg A, Schneider I: In vitro culture of the mosquito stages of Plasmodium falciparum. Exp Parasitol 1993, 76: I21-126.

33. Weathersby $A B$ : The ectopic development of malarial oocysts. Exp Parasitol 1954, 3:538-543.

34. Vlachou D, Schlegelmilch T, Runn E, Mendes A, Kafatos FC: The developmental migration of Plasmodium in mosquitoes. Curr Opin Genet Dev 2006, I 6:384-391.

35. Arrighi RBG, Hurd H: The role of Plasmodium berghei ookinete proteins in binding to basal lamina components and transformation into oocysts. Int ] Parasitol 2002, 32:91-98.

36. Sidén-Kiamos I, Vlachou D, Margos G, Beetsma AL, Waters AP, Sinden RE, Louis C: Distinct roles for Pbs2 I and Pbs25 in the in vitro ookinete to oocyst transformation of Plasmodium berghei. J Cell Sci 2000, I I 3:34 I 9-3426.

37. Dessens JT, Beetsma AL, Dimopoulos G, Wengenlik K, Crisanti A, Kafatos F, Sinden RE: CTRP is essential for mosquito infection by malaria ookinetes. EMBO J 1999, I 8:622 I-6227.

38. Yuda M, Shakaida H, Chinzei Y: Targeted disruption of the Plasmodium berghei CTRP gene reveals its essential role malaria infection of the vector mosquito. J Exp Med 1999 , 190:1711-1715 
39. Schneider D, Shahabuddin M: Malaria parasite development in a Drosophila model. Science 2000, 288:2376-2379.

40. Warburg A, Shtern A, Cohen N, Dahan N: Laminin and a Plasmodium ookinete surface protein inhibit melanotic encapsulation of Sephadex beads in the hemocoel of mosquitoes. Microbes Infect 2007, 9:192-199.

41. Nacer A, Underhill A, Hurd H: The microneme proteins CTRP and SOAP are not essential for Plasmodium berghei ookinete to oocyst transformation in vitro in a cell free system. Malar J 2008, 7:82.

42. Garnham PC, Bird RG, Baker JR, Desser SS, el-Nahal HM: Electron microscope studies on motile stages of malaria parasites. VI. The ookinete of Plasmodium berghei yoelii and its transformation into the early oocyst. Trans R Soc Trop Med Hyg 1969, 63: $187-194$.

43. Sidén-Kiamos I, Louis C: Interactions between malaria parasites and their mosquito hosts in the midgut. Insect Biochem Mol Biol 2004, 34:679-685.

44. Kumagai C, Kadowaki T, Kitagawa Y: Disulfide-bondingbetween Drosophila laminin beta and gamma chains is essential for alpha chain to form alpha betagamma trimer. FEBS Lett 1997, 4I 2:2II-2I6.

45. Aikawa M, Atkinson CT, Beaudoin LM, Sedegah M, Charoenvit $Y$, Beaudoin R: Localization of CS and non-CS antigens in the sporogonic stages of Plasmodium yoelii. Bull World Health Organ 1990, 68(Suppl):|65-|7|.

46. Nagasawa H, Aikawa M, Procell PM, Campbell GH, Collins WE, Campbell CC: Plasmodium malariae: distribution of circumsporozoite protein in midgut oocysts and salivary gland sporozoites. Exp Parasitol 1988, 66:27-34.

47. Nagasawa H, Procell PM, Atkinson CT, Campbell GH, Collins WE, Aikawa M: Localization of circumsporozoite protein of Plasmodium ovale in midgut oocysts. Infect Immun 1987, 55:2928-2932.

48. Thathy V, Fujioka H, Gantt S, Nussenzweig R, Nussenzweig V, Ménard $\mathrm{R}$ : Levels of circumsporozoite protein in the Plasmodium oocyst determine sporozoite morphology. EMBO J 2002, 21:1586-1596.

49. Okuda K, de Souza Caroci A, Ribolla PE, de Bianchi AG, Bijovsky AT: Functional morphology of adult female Culex quinquefasciatus midgut during blood digestion. Tissue Cell 2002, 34:2 10-219.

50. Weaver SC, Scott TW: Ultrastructural changes in the abdominal midgut of the mosquito, Culiseta melanura, during the gonotrophic cycle. Tissue Cell 1990, 22:895-909.

5I. Thompson J, Fernandez-Reyes D, Sharling L, Moore SG, Eling WM, Kyes SA, Newbold CI, Kafatos FC, Janse CJ, Waters AP: Plasmodium cysteine repeat modular proteins I-4: complex proteins with roles throughout the malaria parasite life cycle. Cell Microbiol 2007, 9: | 466- I480.

52. Benchimol M, Batista C, De Souza W: Fibronectin- and lamininmediated endocytic activity in the parasitic protozoa Trichomonas vaginalis and Tritrichomonas foetus. J Submicrosc Cytol Pathol 1990, 22:39-45.

53. Benchimol M, da Cunha e Silva NL, Elias CA, de Souza W: Tritrichomonas foetus: ultrastructure and cytochemistry of endocytosis. Exp Parasitol 1986, 62:405-415.

54. Hohenester E, Engel J: Domain structure and organisation in extracellular matrix proteins. Matrix Biol 2002, 2 I:II5-I28.

55. Blanco ARA, Paez A, Gerold P, Dearsly AL, Margos G, Schwartz RT, Barker G, Rodriguez MC, Sinden RE: The biosynthesis and posttranslational modification of Pbs2 I an ookinete-surface protein of Plasmodium berghei. Mol Biochem Parasitol 1999, 98(2): 163-173.

56. Sinden RE, Barker GC, Paton MJ, Fleck SL, Butcher GA, Waters A, Janse $C$, Rodriguez $\mathrm{MH}$ : Factors regulating natural transmission of Plasmodium berghei to the mosquito vector, and the cloning of a transmission-blocking immunogen. Parassitologia 1993, 35(Suppl): 107-II2.

57. Reinhardt $\mathrm{C}, \mathrm{Hecker} \mathrm{H}$ : Structure and function of the basal lamina and of the cell junctions in the midgut epithelium (stomach) of female Aedes aegypti L.(Insecta, Diptera). Acta Trop 1973, 30:213-236.

58. Sodja A, Fujioka H, Lemos FJ, Donnelly-Doman M, Jacobs-Lorena M: Induction of actin gene expression in the mosquito midgut by blood ingestion correlates with striking changes of cell shape. J Insect Physiol 2007, 53:833-839.
59. Smedsrod B, Paulsson M, Johansson S: Uptake and degradation in vivo and in vitro of laminin and nidogen by rat liver cells. Biochem J 1989, 26 1:37-42.

60. Rizki TM, Rizki RM: The cellular defense system of Drosophila melanogaster. In Insect Ultrastructure Volume 2. Edited by: King RC, Akai H. New York: Plenum Publishing; 1984:579-603.

6I. Hirai M, Arai M, Kawai S, Matsuoka H: PbGCbeta is essential for Plasmodium ookinete motility to invade midgut cell and for successful completion of parasite life cycle in mosquitoes. Biochem 2006, 140:747-757.

62. Nardi JB: Embryonic origins of the two main classes of hemocytes - granular cells and plasmatocytes - in Manduca sexta. Dev Genes Evol 2004, 2 I 4: 19-28.

63. Liu CT, Hou RF, Chen CC: Formation of basement membranelike structure terminates the cellular encapsulation of microfilariae in the haemocoel of Anopheles quadrimaculatus. Parasitology 1998, I I6(Pt 6):5II-5I8.

64. Mahairaki V, Lycett G, Siden-Kiamos I, Sinden RE, Louis C: Close association of invading Plasmodium berghei and beta integrin in the Anopheles gambiae midgut. Arch Insect Biochem Physiol 2005, 60:13-19.

65. Franke-Fayard B, Trueman HE, Ramesar J, Mendoza J, Keur Mvan der, Linden $\mathrm{R}$ van der, Sinden RE, Waters AP, Janse Cl: A Plasmodium berghe $i$ reference line that constitutively expresses GFP at a high level throughout the life cycle. Mol Biochem Parasitol 2004, I37(I):23-33

66. Mahendrasingam S, Wallam CA, Polwart A, Hackney CM: An immunogold investigation of the distribution of GABA and glycine in nerve terminals on the somata of sperical bushy cells in the anteroventral cochlear nucleus of the guinea pig. Eur J Neurosci 2004, 19:993-1004.

67. Geneious v2.5 [http://www.geneious.com]

68. Zar JH: Biostatistical Analysis 4th edition. Upper Saddle River, N.J.: Prentice Hall International Editions; 1999.
Publish with Bio Med Central and every scientist can read your work free of charge

"BioMed Central will be the most significant development for disseminating the results of biomedical research in our lifetime. "

Sir Paul Nurse, Cancer Research UK

Your research papers will be:

- available free of charge to the entire biomedical community

- peer reviewed and published immediately upon acceptance

- cited in PubMed and archived on PubMed Central

- yours - you keep the copyright
BioMedcentral 